\title{
Towards process intensification: Remediation of fouling in continuous microscale synthesis of phosphated $\mathrm{TiO}_{2}$
}

\author{
Martin Hochstrasser ${ }^{1}$, Daniel Jussen ${ }^{1}$, Peter Riedlberger* \\ Research Group Chemical Engineering, Institute of Chemistry and Biotechnology, Zurich University of Applied Sciences, Wädenswil, Switzerland
}

\begin{abstract}
A B S T R A C T
The use of continuous flow microreactors offers an interesting approach among the process intensification tools available. Fouling in a microreactor during synthesis of industrially relevant nanoparticles was investigated. In order to achieve this, microscale synthesis of phosphated $\mathrm{TiO}_{2}$ nanoparticles from titanium(IV) isopropoxide (TTIP) and titanium(IV) butoxide (TBUT) was employed. A continuous three step process, consisting of hydrolysis of the respective alkoxide, phosphate modification and precipitation was developed. The resulting catalyst was characterized by means of nitrogen adsorption, dynamic light scattering and SEM/EDX. It was observed that TTIP resulted in massive fouling, while a stable process was possible with TBUT. This was related to the nucleation time of the particles. The particle size directly after the critical hydrolysis step was investigated. The particles formed with TTIP as a precursor $(3.4 \mathrm{~nm})$ were larger than those obtained from TBUT $(2.4 \mathrm{~nm})$. Diffusion based reactant concentration gradients within the multilamellar micromixer were calculated, and the corresponding Damköhler numbers for mixing were estimated to be $2 \cdot 6 \cdot 10^{-3}$ for TBUT and $3.5 \cdot 10^{-2}$ for TTIP respectively. These numbers highlight the influence of incomplete mixing on fouling for TTIP as a precursor. Thus, our work demonstrates the necessity to consider the reaction kinetics during process intensification by miniaturization.
\end{abstract}

\section{Introduction}

Process intensification (PI) plays a major role in approaches adopted in green chemistry. While numerous different methods and definitions are present, a generalized definition has been supplied by Stankiewicz et al. They conclude that all common definitions of process intensification can be reduced to the key aspect to use innovative measures in order to achieve a substantial improvement [1]. Continuous processing and process miniaturization are, especially when combined, very interesting routes towards an intensified process [2]. The increased control over heat and mass transfer, the ease of serial reactions and increased active surface to volume ratio (i.e. for catalysis) allow for faster reaction rates, lower energy consumption and higher yields [3-7]. These advantages, but also the possibility to use more severe process conditions, have become the driving forces for intensification by miniaturization [2,7-13]. The use of batch and continuous microreactor technology involving solids (i.e. catalysts) has become an interesting new field in (bio)catalysis [14-18]. Miniaturization of chemical fluid and gas phase reactions is a promising approach for industrial application; however, continuous microreactor processing involving solids is much less popular [3]. One of the main obstacles for the downscale and intensification of chemical processes involving solids is the fouling and clogging of microstructured devices [19-24]. Despite the obstacles, green and intensified microreactor routes for nanoparticle synthesis are most desirable as nanoparticles have become invaluable not only as catalysts, for optoelectronics and nanomedicine [25], but also in everyday applications [26]. $\mathrm{TiO}_{2}$ nanoparticles in particular play an important role due to their diverse application in sunscreen, paints, toothpaste, solar cells, electrochemical electrodes, capacitators and heterogeneous catalysis $[27,28]$. The increasing production of $\mathrm{TiO}_{2}$ nanoparticles in the last five years from between 3300 and 13000 tons per year in 2011 [29] to an estimated 50.000 tons in 2016 [30] as well as the predicted production of 2.5 million tons in 2025 [31] clearly underline the industrial relevance of flexible and sustainable $\mathrm{TiO}_{2}$ synthesis processes.

Synthesis of $\mathrm{TiO}_{2}$ nanoparticles is of great interest and has been reviewed thoroughly $[27,32]$. While there are different synthesis routes towards $\mathrm{TiO}_{2}$-nanoparticles which can be adopted, including sol-gel, microemulsion, precipitation, hydrothermal, solvothermal, electrochemical and biological synthesis of $\mathrm{TiO}_{2}$ nanoparticles [32,33], the

\footnotetext{
* Corresponding author at: Research Group Chemical Engineering, Institute of Chemistry and Biotechnology, Zurich University of Applied Sciences, Einsiedlerstrasse 31, 8820 Wädenswil, Switzerland.

E-mail address: peter.riedlberger@zhaw.ch (P. Riedlberger).

${ }^{1}$ Contributed equally.
} 


\section{Nomenclature}

List of abbreviations

$\begin{array}{ll}\text { PI } & \text { Process intensification } \\ \text { TTIP } & \text { Titanium(IV)isopropoxide } \\ \text { TBUT } & \text { Titanium(IV)butoxide } \\ \text { 5-HMF } & \text { 5-Hydroxymethylfurfural } \\ \text { THF } & \text { Tetrahydrofuran } \\ \text { NMP } & \text { N-methyl-2-pyrrolidone } \\ \text { HPLC } & \text { High performance liquid chromatography } \\ \text { BET } & \text { Gas adsorption according to Stephen Brunauer, Paul Hugh } \\ & \text { Emmett and Edward Teller } \\ \text { BJH } & \text { Method to calculate pore size distribution according to } \\ & \text { barrett-Joyner-Halenda } \\ \text { P-TiO }_{2} & \text { Phosphate modified titaniumdioxide }\end{array}$

SEM/EDXScanning electron microscope/energy-dispersive X-ray spectroscopy

List of Symbols

$\mathrm{C}_{\mathrm{n}} \quad$ Alkoxide concentration $\left(\mathrm{mol} \mathrm{L}^{-1}\right)$

$\mathrm{C}_{\mathrm{w}} \quad$ Water concentration $\left(\mathrm{mol} \mathrm{L}^{-1}\right)$

$\mathrm{Da}_{\mathrm{m}} \quad$ Damköhler number for mixing

$\mathrm{D}_{\mathrm{p}} \quad$ Particle diameter $(\mathrm{nm})$

Pe Peclet number

St Stokes number

$t_{D} \quad$ Characteristic diffusion time (s)

$\mathrm{t}_{\mathrm{F}} \quad$ Characteristic flow time (s)

$\mathrm{t}_{\text {ind }} \quad$ Induction time (s)

$\mathrm{t}_{\mathrm{M}} \quad$ Mixing time (s)

$t_{\mathrm{P}} \quad$ Particle relaxation time (s)

$t_{R} \quad$ Reaction time (s) sol-gel process from titanium(IV)alkoxides and water in the parent solvent of the respective alkoxide is of special interest due to its mild reaction conditions. The reaction is especially dependent on the hydrolysis ratio and the ratio of water to alkoxide. Additionally, it may be tuned by use of both acid and base content, solution composition and temperature. Ambient temperature, product homogeneity, low temperature sintering and ease of functionalization of the resulting nanomaterials are further advantages of this synthesis route [32,34,35]. In order to estimate the influence of mixing efficiency on particle formation and fouling, the reaction as well as mixing time can be utilized. The respective kinetics of the particle formation were studied thoroughly. Thus, the sol-gel $\mathrm{TiO}_{2}$-synthesis, as a well-known process of industrial interest, is especially suited for exemplary downscale into the microreactor and fouling investigation. Azouani et al. observed that initial particle nucleation at a radius of $\sim 2.6 \mathrm{~nm}$ by initial hydrolysis takes place almost instantaneously [36]. Afterwards, if the hydrolysis ratio and $\mathrm{pH}$ are tuned accordingly, a near linear increase of the particle radius up to the nucleation point at around $4 \mathrm{~nm}$ is observed. As soon as particle radius has reached $\sim 4 \mathrm{~nm}$, aggregation of particles occurs and the particle size increases rapidly $[37,38]$. The kinetics of the nucleation, based on a power law relation, have been elaborated by numerous studies [36-40]. Induction time kinetics for TTIP have been proposed by Soloviev et al. (Eq. (1)) [36-38]. They proposed a model including a correction term for initial hydrolysis with $\mathrm{k}$ as rate constant, $\mathrm{C}_{\mathrm{n}}=$ TTIP concentration and $\mathrm{C}_{\mathrm{w}}$ as water concentration.

$\mathrm{t}_{\text {ind }}=\mathrm{k} \cdot \mathrm{C}_{\mathrm{n}}^{-1.5}\left(\mathbf{C}_{\mathrm{w}}-1.45 \mathrm{C}_{\mathrm{n}}\right)^{-4.7}$

An analogous model, but without the respective correction term for initial hydrolysis, was developed by Golubko et al. for TBUT [39], as stated in Eq. (2).

$\mathbf{t}_{\text {ind }}=\mathbf{k} \cdot \mathbf{C}_{\mathbf{n}}^{-2}\left(\mathbf{C}_{\mathbf{w}}\right)^{-5}$

Nucleation time kinetics have previously been used by Mohamedani et al. to explain mixing and nucleation phenomena in $\mathrm{TiO}_{2}$ synthesis in a spinning disc reactor [40]. During the particle formation, $\mathrm{pH}$ plays an important role in stabilization of $\mathrm{TiO}_{2}$-nanoparticles below the nucleation point. Simonsen et al. reported formation of larger particles only at a $\mathrm{pH}$ above 3 , with nucleation rate increasing with $\mathrm{pH}$ for both TTIP and TBUT [41]. This is due to the dependence of the particle's zeta potential on the presence of acids and bases. However, the fact that $\mathrm{pH}$ values were measured in the respective parent alcohol of the titanium (IV)alkoxide used has to be taken into account. The topic of $\mathrm{pH}$ determination in organic solvents and the measurement thereof is still under investigation and different approaches have been published $[42,43]$. The use of the $\mathrm{pH}$ value by Simonsen et al., based on $\mathrm{H}_{3} \mathrm{O}^{+}$ion concentration in organic solvents, does not reflect the original auto hydrolysis definition of $\mathrm{pH}$ in water. For the present paper the apparent $\mathrm{pH}$ is introduced as a term to describe $\mathrm{pH}$ values derived from the simulated hydrolysis of water by nitric acid in n-butanol and 2-propanol as solvents by assuming complete hydrolysis. Despite the difficulty of $\mathrm{pH}$ definition, addition of a strong acid allows prevention of particle aggregation during the $\mathrm{TiO}_{2}$-sol-gel synthesis [41].

$\mathrm{TiO}_{2}$ can be synthesised as amorphous material as well as in three different crystal forms, namely brookite, rutile and anatase. On the surface of anatase, $\mathrm{TiO}_{2}$ crystals have a lower coordination number than within the crystal lattice. Those sites are called coordinatively unsaturated surfaces. Due to their unsaturated coordination, those sites show Lewis acid activity. This activity can be utilized for catalysis such as the access of 5-hydroxymethylfurfural (5-HMF) from carbohydrates. 5 -HMF has great potential for industrial application. It serves as a substrate for the oxidation to 2,5-dicarboxylic acid, a potential replacement of terephthalic and other fossil based diacids for the synthesis of bioplastics. Other interesting products to be synthesised from 5HMF are dimethylfuran and 2-methylfuran, which may serve as biofuels $[34,44]$. The works of Nakajima et al. and Atanda et al. optimized the catalytic performance of $\mathrm{TiO}_{2}$ for 5-HMF synthesis by phosphate modification of anatase nanoparticles through addition of phosphoric acid or ammonium phosphate during the process. The resulting catalyst, in combination with a biphasic solvent, produced yields of $80 \%$ and drastically reduced the formation of undefined polymers during the reaction $[34,44-46]$. This novel phosphate doped $\mathrm{TiO}_{2}$ catalyst is a promising candidate for further process optimization.

Utilization of micromixers for rapid mixing of reactants plays an important role during the design of microreaction systems, especially in the case of solid particle synthesis. However, industrial application is often inhibited by fouling [3]. Kockmann et al. identify two dimensionless numbers as boundary conditions for the deposition process. The Péclet Number $(P e)$ has been defined as the ratio of characteristic diffusion time $\left(t_{D}\right)$ and characteristic flowtime $\left(t_{F}\right)$, while the Stokes Number $(S t)$ provides the relation of the particle relaxation time $\left(t_{P}\right)$ and the characteristic flow time, as denoted in Eqs. (3) and (4). Further information on Péclet and Stokes Numbers is provided in the Supplementary information (SI) (Eqs. (10)-(14)).

$P e=\frac{t_{\mathrm{D}}}{t_{\mathrm{F}}}$

$S t=\frac{t_{\mathrm{P}}}{t_{\mathrm{F}}}$

Despite the outcome of their study that no universal fouling remediation strategy can be applied but that an individual approach is necessary for each microreactor process, a Péclet number smaller than $5 \cdot 10^{6}$ to prevent particle deposition by diffusion and a Stokes number 
smaller than $5 \cdot 10^{-2}$ to avoid particle deposition at the wall by inertia are suggested [19].

The concept of the Damköhler number $D a_{m}$ for mixing as the relation of mixing time and reaction time is stated in Eq. (5). $t_{R}$ denounces the reaction time and $t_{M}$ the mixing time. This Damköhler number provides a simple approach to estimate whether mixing phenomena have an impact on the reaction kinetics [47-50].

$D a_{m}=\frac{t_{\mathrm{M}}}{t_{\mathrm{R}}}$

In general, a Damköhler number for mixing smaller than $10^{-2}$ is necessary to prevent significant impact of mixing phenomena on product formation kinetics. The relevance of the Damköhler number for mixing in microscale $\mathrm{TiO}_{2}$-nanoparticle synthesis has been demonstrated by Azouani et al., who adapted the flow rate to increase the Reynolds number and thus decrease the effect of mixing on reaction rate [51].

Our aim was to investigate and optimize fouling within an industrially relevant microreactor system to provide data for fouling remediation during intensification of processes involving solids. Therefore, this work exemplarily shows the miniaturization of phosphated $\mathrm{TiO}_{2}$ nanoparticle synthesis as a multistep continuous microreactor process utilizing a modular microreactor setup. Continuous multistep synthesis is achieved by serial setup of a slit plate- [52,53], a comb [54] and a valve mixer [55-57]. Both titanium(IV)isopropoxide (TTIP) and titanium(IV)butoxide (TBUT) are investigated as precursors for the reaction in order to elucidate the influence of mixing and reaction speed on fouling in a continuous microreactor process. The respective particles are characterized according to their physical and chemical properties by means of nitrogen adsorption, dynamic light scattering (DLS) and SEM/EDX. The resulting catalyst is then exemplarily used to catalyse the conversion of glucose to 5-HMF.

\section{Methods}

\subsection{Materials}

Titanium(IV)isopropoxide ( $\geqq 97 \%$ ), Titanium(IV)butoxide ( $\geqq 97 \%$ ), 2-propanol ( $\geqq 99.8 \%$ ), ammonium hydroxide solution (25\%), HMF, glucose ( $\geqq 96 \%)$, fructose ( $\geqq 99 \%)$, phosphoric acid (85\%), N-methyl-2pyrrolidone (NMP) ( $\geqq 99 \%$ ), tetrahydrofuran (THF) ( $\geqq 99 \%)$ and sodium hydroxide $(\geqq 97 \%)$ were purchased from Sigma-Aldrich. Nitric acid (65\%) was purchased from Carl Roth (Arlesheim, Schweiz). Millipore water with a conductivity of $0.055 \mathrm{mS} \mathrm{cm}^{-1}$ was used. All materials were used without further purification.

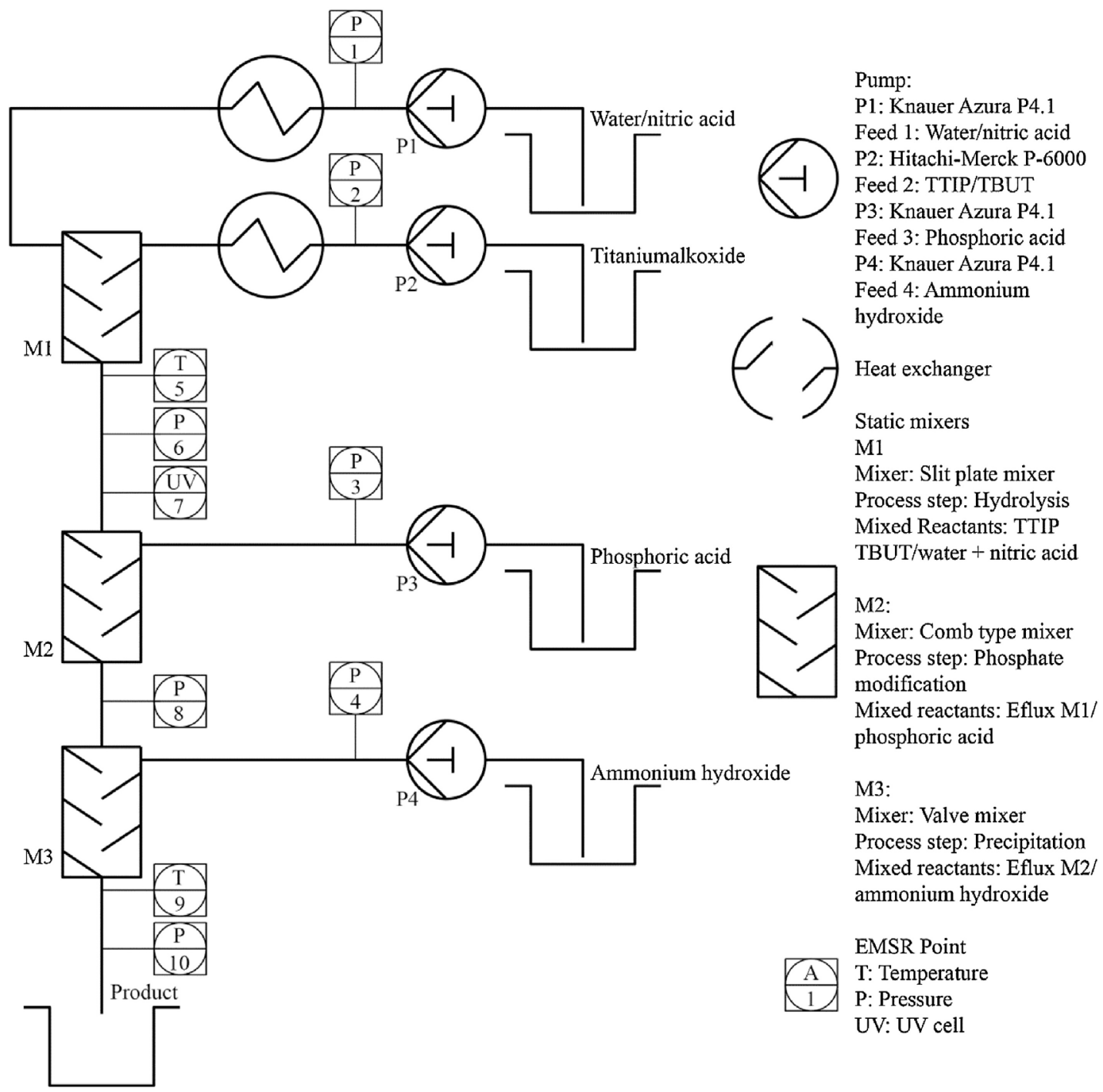

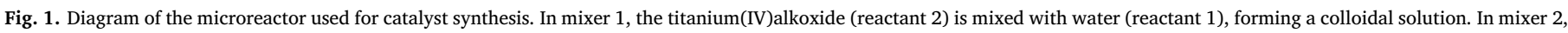
phosphoric acid solution (reactant 3) is added and in the last stage ammonium hydroxide solution (reactant 4) is admixed to precipitate the phosphate modified titania. 


\subsection{Catalyst synthesis}

A modular microreactor (Ehrfeld Mikrotechnik, Wendelsheim, Germany) was used for the continuous flow catalyst synthesis (see Fig. 1). A detailed list of the microreactor modules used in this study is provided in the SI (Table 9). In the first stage, a solution of $1.79 \mathrm{~g}$ water, $5.01 \mathrm{~g}$ nitric acid and $91.24 \mathrm{~g}$ 2-propanol was mixed with $18.36 \mathrm{~g}$ TTIP, dissolved in $44.65 \mathrm{~g}$ 2-propanol, in a slit plate mixer. Subsequently, $1.01 \mathrm{~g}$ phosphoric acid dissolved in $123.62 \mathrm{~g}$ 2-propanol was added to the reaction by use of a comb-type mixer. Finally, a solution of $14.79 \mathrm{~g}$ water, $4.93 \mathrm{~g}$ ammonium hydroxide solution (25\%) and $136.80 \mathrm{~g} \mathrm{2-}$ propanol was added in a valve mixer. Volume flow rates of pumps 1-4 were set to $2,2,2.6$ and $3.2 \mathrm{~mL} \mathrm{~min}^{-1}$, respectively. Pump performance was controlled gravimetrically and were within $\pm 5 \%$ of the set point values. Temperature after the slit-plate mixer was set to $75{ }^{\circ} \mathrm{C}$ and control was achieved by heating feed 1 and 2. For thermal equilibration, feed one was switched on and feed 2 was set to pure 2-propanol/ butanol. Once the reaction temperature of $75^{\circ} \mathrm{C}$ in the first mixer was achieved, feed 2 was switched to TTIP solution and the reaction was thus started. 10 min later, a sample was collected at the outlet of the multimixer setup for determination of primary particle size by DLS. Thereafter, feeds 3 and 4 were switched on. The white product solution at the end of the microreactor was collected. Additionally, primary particle formation was analysed directly after the first slit plate mixer to investigate the fouling mechanism and behaviour of different substrates.

The suspension was centrifuged for $15 \mathrm{~min}$. The solids were washed twice with acetone and once with hexane as a solvent. For each washing step, the sediment was re-suspended in $20 \mathrm{~mL}$ of solvent by stirring and 5 min of ultrasonic treatment. For better sedimentation during centrifugation, $150 \mu \mathrm{L}$ of ammonium hydroxide solution (25\%) were added for each washing step.

The received sediment was dried for $12 \mathrm{~h}$ in vacuum at $80{ }^{\circ} \mathrm{C}$, followed by $4 \mathrm{~h}$ at $120^{\circ} \mathrm{C}$. The dried sediment was heated at a rate of $5{ }^{\circ} \mathrm{C} \min ^{-1}$ and kept at $600{ }^{\circ} \mathrm{C}$ for $3 \mathrm{~h}$ in static air. Experiments were carried out twice for consistency.

\subsection{Catalyst characterization}

Primary particle size was measured by DLS using a Malvern Zetasizer Nano ZEN3600 (Malvern Instruments, Herrenberg, Germany) equipped with a $633 \mathrm{~nm}$ laser. Colloidal samples were measured without prior dilution.

The specific surface area was determined at $350.15{ }^{\circ} \mathrm{C}$ on a NOVA3000 (Quantachrome, Boynton Beach, USA) instrument by nitrogen adsorption and evaluation using the gas adsorption method according to Stephen Brunauer, Paul Hugh Emmett and Edward Teller (BET) method [58]. For the porosity calculation, the isotherm was evaluated according to the method by Barrett-Joyner-Halenda (BJH) method [59]. The catalyst was dried at $80{ }^{\circ} \mathrm{C}$ for $4 \mathrm{~h}$ prior to nitrogen adsorption measurements.

Scanning electron microscope images were collected on a Quanta FEG 250 instrument (FEI, Hillsboro, USA) at an acceleration voltage of $10 \mathrm{kV}$. The catalyst was fixed on carbon tape without any sputtering. Phosphorous/titanium composition was verified using an EDX detector.

Raman spectra were recorded using an Alpha UHTS 300 (WITec, Ulm, Germany) with a $532 \mathrm{~nm}$ laser.

For catalytic conversion of glucose to 5-HMF, $0.52 \mathrm{~g}$ of glucose and $0.40 \mathrm{~g}$ of sodium chloride were dissolved in $2 \mathrm{~mL}$ of water. $6 \mathrm{~mL}$ THF, $2 \mathrm{~mL}$ NMP and $0.125 \mathrm{~g}$ of catalyst were added. The reaction was carried out in a microwave reactor (Biotage, Uppsala, Sweden) at $175^{\circ} \mathrm{C}$ for $105 \mathrm{~min}$. After centrifugation for $10 \mathrm{~min}$, the liquid was decanted and the two phases separated.

\subsection{HMF quantification}

5-HMF, fructose und glucose were quantified by HPLC using a Nucleogel Sugar 810H VA 300/7.8 column (Macherey-Nagel, Düren, Germany). The calibration range was $0.1-2 \mathrm{~g} \mathrm{~L}^{-1}$. A 1200 Series (Agilent Technologies, Santa Clara, USA) HPLC system was used. The chromatography was carried out in isocratic mode. The mobile phase was a mixture of $90 \%$ acetonitrile and $10 \%$ water containing $0.1 \%$ trifluoroacetic acid. The flow was $0.4 \mathrm{~mL} \mathrm{~min}^{-1}$ for $45 \mathrm{~min}$. For detection, a G1315C diode array detector at $275.4 \mathrm{~nm}$ (Agilent Technologies, Santa Clara, USA) for 5-HMF and a 1290 Infinity II evaporative light scattering detector (Agilent Technologies, Santa Clara, USA) for glucose and fructose were used. Retention times were 12.8 for glucose, 14.2 for fructose and $38.2 \mathrm{~min}$ for 5-HMF respectively.

\subsection{Modelling of the mixing in the LH2 slit plate mixer}

Python 2.73 (Python Software Foundation, Delaware, USA) was used for the modelling of the diffusion based mixing within the Ehrfeld LH2 slit plate mixer used as mixer one (for a detailed list of the microreactor modules used, please refer to Table 8 in the SI). The respective diffusion model according to the Einstein Smoluchowski relation (SI; Eq. (15)) and Fick's second law of diffusion (SI; Eq. (7)) is elaborated in detail in the (SI). Van der Waals radii of molecules were estimated using MarvinSketch 16.10.3.0 (ChemAxon, Budapest, Hungary).

\section{Results}

\subsection{Localization of fouling}

Pressure measurement within the microreactor system was used as an indicator for fouling during catalyst synthesis. As can be seen from the pressure curves depicted in Fig. 2, the first reaction step is, when utilizing TTIP as a precursor, subjected to a massive increase in process pressure up to 60 bar (solid line). Often, the setup would clog completely before significant amounts of product were obtained. Interestingly, the pressure increase, indicating fouling within the reactor/micromixers, is not observed if TBUT is used as a precursor (dashed line). Additionally, no $\mathrm{TiO}_{2}$ residue in the micromixer was found for TBUT as precursor. Fouling in the first mixing step was identified as the cause of the pressure increase. It was postulated that particles formed before a homogeneous mixture of the TTIP- and water feed was achieved. Thus, inhomogeneous reactant concentrations and $\mathrm{pH}$ resulted in undesired rapid particle formation kinetics and insufficient stabilization of the

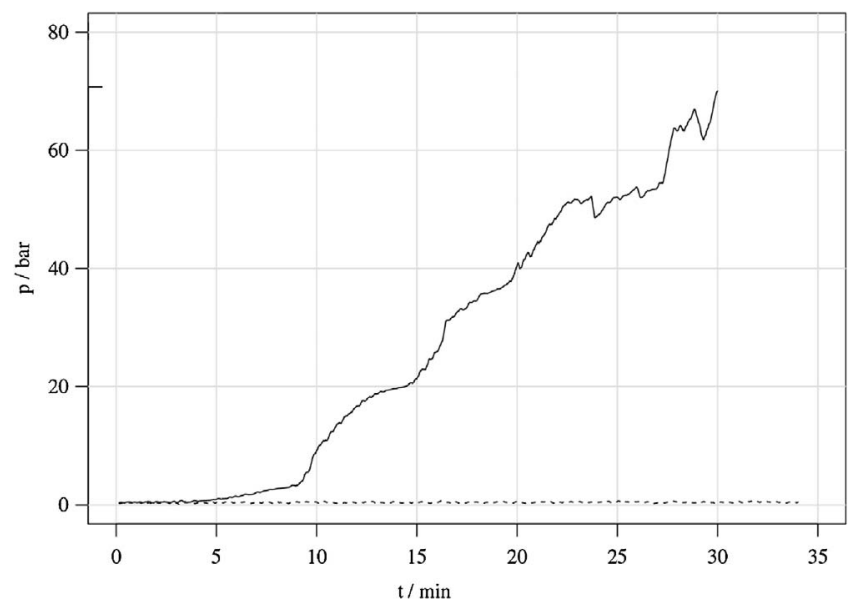

Fig. 2. Exemplary pressure increase of the LH2 slit plate micromixer mixing (Water/ Nitric acid and the respective titanium(IV)alkoxide for TTIP (solid line) and TBUT (dotted line)). 


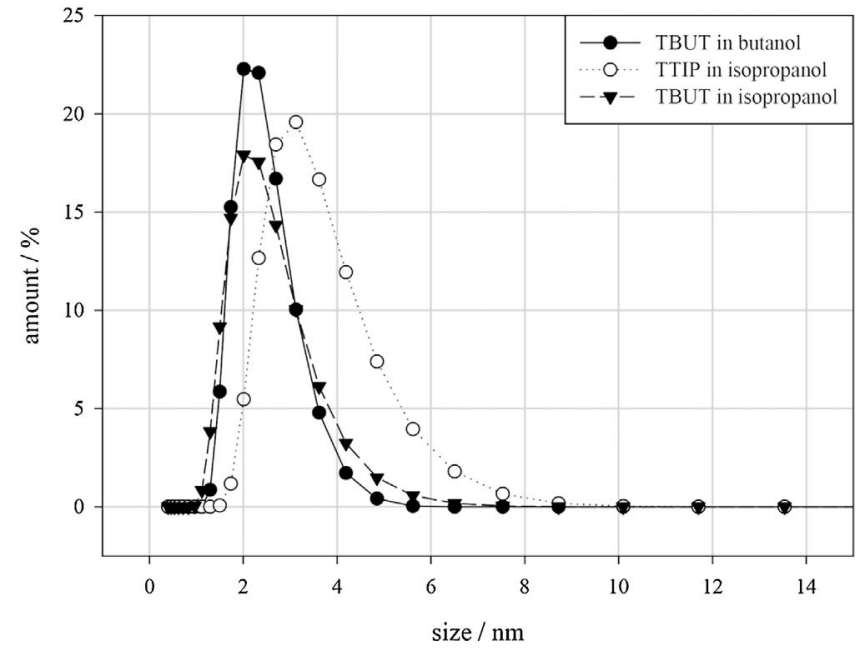

Fig. 3. Particle size of $\mathrm{TiO}_{2}$ particles directly after the first mixer for TBUT in Butanol (solid line), TBUT in isopropanol (dashed line) and TTIP in isopropanol (dotted line).
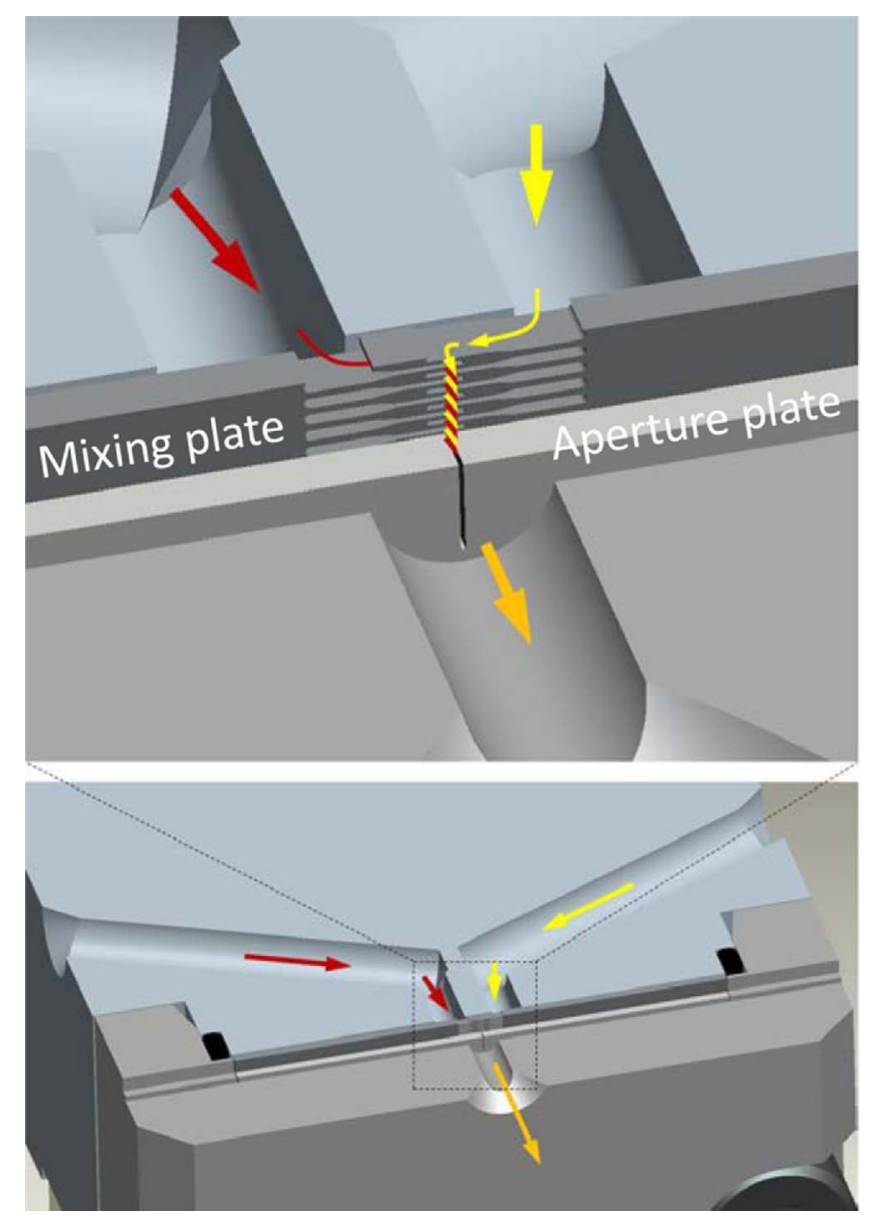

Fig. 4. Mixing principle of the Ehrfeld LH2 slit plate multilamellation mixer (with permission of Ehrfeld Mikrotechnik BTS) [62].

particles. This is supported by the lack of fouling for the less reactive TBUT and the lack of significant fouling in the consecutive mixers. It was furthermore observed that older TTIP and 2-propanol batches caused even more massive fouling (data not shown). This phenomenon has previously been reported, as the hygroscopic properties of 2-propanol can cause a decrease in observed nucleation time of $\mathrm{TiO}_{2}$ [37]. One of the causes for the fouling may thus be water contamination in the TTIP feed. In this case, the nucleation would already have started before entering the mixing region. Another possible explanation is the faster reaction rate of TTIP compared to TBUT. Therefore, the reaction with TTIP reaches critical particle size before mixing is complete, resulting in particle deposition and agglomeration, thus causing fouling.

\subsection{Investigation of fouling causes}

To further investigate the fouling, the primary particle size directly after the first mixer was measured for three different precursor-solvent combinations: TBUT in n-butanol, TBUT in 2-propanol and TTIP in 2propanol. TTIP in n-butanol was not investigated due to the higher reactivity of TTIP compared to TBUT because a reaction, analogous to the production of TBUT from titanium(IV)chloride with n-butanol [60], was expected to influence respective experiments. The average primary particle size measured directly after the hydrolysis step of the TTIP produced particles was larger $(3.4 \pm 0.1 \mathrm{~nm})$ than the primary particle size measured at the end of the reactor $(2.2 \pm 0.1 \mathrm{~nm})$. The decrease in size over the second and third process step can be explained by a homogenization effect due to shear stress in the valve mixer (third mixer). Despite the fact that homogenization of particles has not been described for this mixer, the strong emulsifying effect of the valve mixer described in literature [61] underline this coherence. After the slit plate mixer, the two samples with TBUT, in butanol $(2.4 \pm 0.7 \mathrm{~nm})$ and 2propanol $(2.4 \pm 0.5 \mathrm{~nm})$, both resulted in a smaller primary particle size than the sample with TTIP in 2-propanol. For TBUT as a precursor, the particle size directly after the slit plate mixer did not differ from that at the end of the consecutive three step reaction setup. $14 \%$ of particles within the TTIP sample were larger than $4.8 \mathrm{~nm}$, while this fraction included only $0.5 \%$ (in butanol) and $2.4 \%$ (in 2-propanol) for the TBUT samples (Fig. 3). Thus, the TTIP in 2-propanol sample was the only precursor combination tested that included significant particle amounts $\geqq 5 \mathrm{~nm}$. This number is provided by Ehrfeld BTS Mikrotechnik as the maximum particle size to be used within the LH2 slit plate mixer. The effect of 2-propanol hygroscopicity alone does not sufficiently explain these results. If this were the case, the tests with TBUT in 2-propanol should have produced similarly large particles as in the experiments with TTIP. However, the large number of particles sized larger than $2.6 \mathrm{~nm}(80 \%)$ in the TTIP sample in presence of nitric acid $(\mathrm{pH}<3)$ are unusual and indicate non-optimal mixing due to a nucleation time smaller or close to the order of magnitude of the mixing time. Such effects are well known in continuous processing and mixing [47-51].

The mixing times for the different compounds were estimated to be between $1.72 \mathrm{~s}$ (TTIP in 2-propanol) and $0.47 \mathrm{~s}\left(\mathrm{H}_{2} \mathrm{O}\right.$ in 2-propanol) according to manufacturer information (further information in Eq. (8) of the SI). However, the relevant timeframe for fouling within the microstructures is the first millisecond after the fluid passes through the multilamellation structure. During this time, the reactant flow passes through the microscale slit of the aperture plate (Fig. 4). Thus, any accumulation of particles within the mixing structure takes place within this timeframe. The concentration gradients of reactants, $\mathrm{H}_{3} \mathrm{O}^{+}$and $\mathrm{NO}_{3}{ }^{-}$, as well as the hydrolysis ratio during the first mixing operation, were thus postulated as a fouling cause.

\subsection{Mixing simulation in the LH2 slit plate micromixer}

To elucidate the reactant distribution within this critical timeframe, the diffusion-based mixing at the border between two fluid lamellae within the LH2 slit plate mixer was further investigated by diffusion simulation. An explanatory figure for the multilamellation mixing, as employed in the LH2 slit plate mixer, is displayed in Fig. 4.

The reactant concentrations and the apparent $\mathrm{pH}$ depicted in Fig. 5, as elaborated in the Introduction, clearly show that the reaction conditions within the critical microstructured part of the LH2 slit plate mixer are not homogeneous. The hydrolysis ratio (Fig. 5b), which strongly determines reaction rate/nucleation time, is significantly 
A

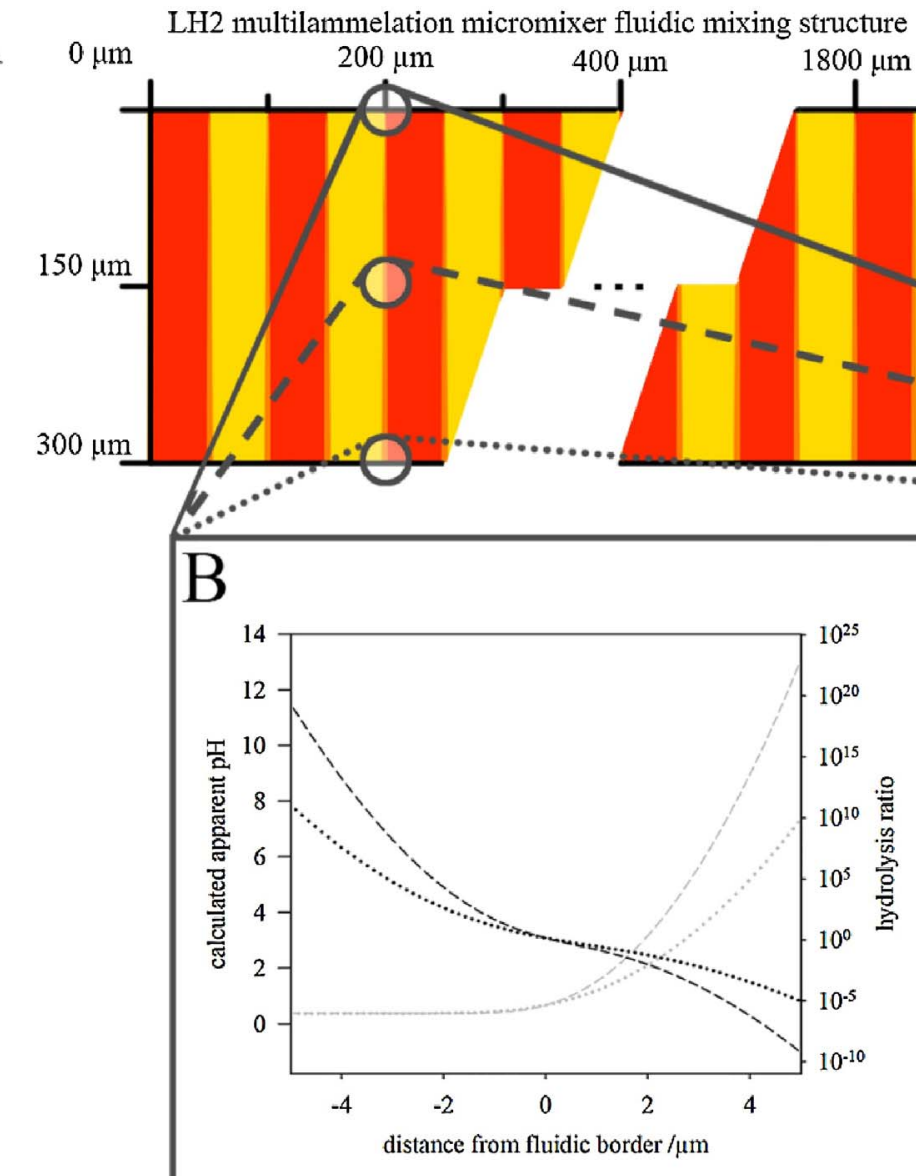

LH2 multilammelation micromixer fluidic mixing structure

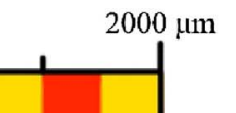

TTIP precursor

water + nitric acid

C

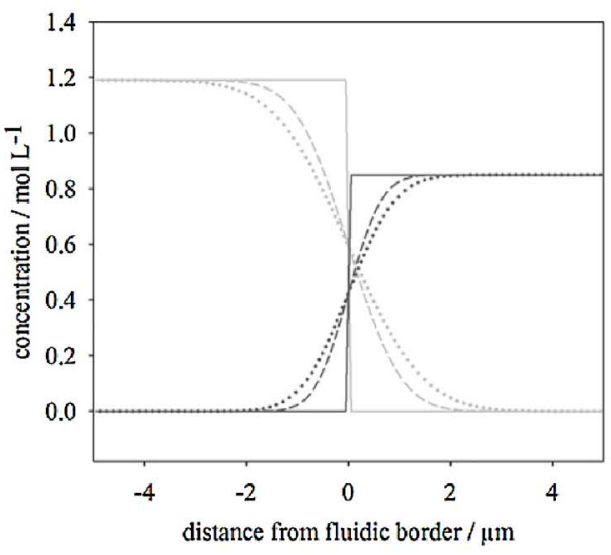

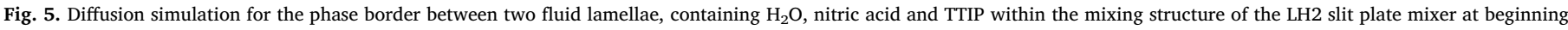

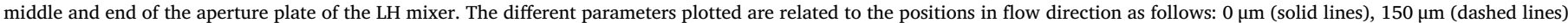

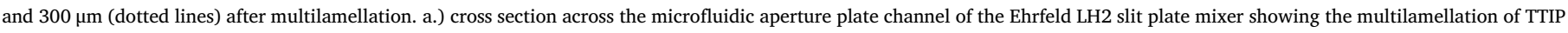

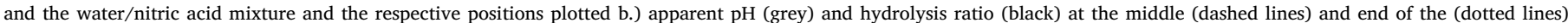

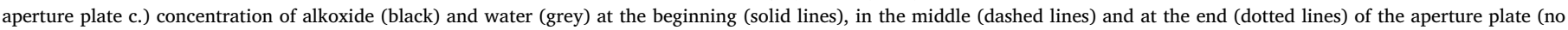
significant difference was determined between TTIP and TBUT, the respective figure for TBUT as a precursor can be found in the SI, Fig. 1).

Table 1

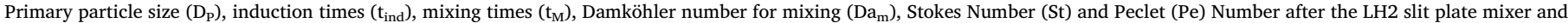
relevant characterization numbers for the hydrolysis reaction step.

\begin{tabular}{|c|c|c|c|c|c|c|}
\hline Substrate & $\mathrm{D}_{\mathrm{P}}(\mathrm{nm})[\mathrm{m} / \mathrm{a} / \mathrm{x}]^{\mathrm{a}}$ & $\mathrm{Da}_{\mathrm{m}}$ & $\mathrm{t}_{\text {ind }}(\mathrm{s})$ & $\mathrm{t}_{\mathrm{M}}(\mathrm{s})$ & $\operatorname{Pe}[\mathrm{m} / \mathrm{a} / \mathrm{x}]^{\mathrm{a}}$ & St $[\mathrm{m} / \mathrm{a} / \mathrm{x}]^{\mathrm{a}}$ \\
\hline TTIP & $1.5 / 3.4 / 10.1$ & $3.5 \cdot 10^{-2}$ & 33 & 1.15 & $4.4 \cdot 10^{8} / 1.01 \cdot 10^{9} / 2.99 \cdot 10^{9}$ & $4.98 \cdot 10^{-6} / 2.56 \cdot 10^{-5} / 2.26 \cdot 10^{-4}$ \\
\hline TBUT & $1.3 / 2.4 / 5.6$ & $2.6 \cdot 10^{-3}$ & 657 & 1.72 & $5.31 \cdot 10^{8} / 9.8 \cdot 10^{8} / 2.29 \cdot 10^{9}$ & $3.01 \cdot 10^{-6} / 6.40 \cdot 10^{-5} / 3.48 \cdot 10^{-4}$ \\
\hline
\end{tabular}

${ }^{\mathrm{a}}$ The indexes $[\mathrm{m} / \mathrm{a} / \mathrm{x}]$ refer to the respective values for minimum, average and maximum particle size as determined by DLS measurement.

influenced by the diffusion gradient. It becomes very large and approaches infinity when the alkoxide concentration approaches 0 . The simulated concentration data for $\mathrm{H}_{2} \mathrm{O}$ and TTIP in Fig. 5b additionally elucidate the concentration gradients at the lamellae interfaces within the micromixing structure. The simulation data revealed that regions with an alkoxide concentration in the $10^{-1} \mathrm{~mol} \mathrm{~L}^{-1}$ order of magnitude and a hydrolysis ratio between 2 and 10 are present close to the liquid interfaces. These results obtained for one interface region can be extrapolated for all the interfaces between the 40 fluid lamellae. These areas, with sufficient alkoxide concentration to allow a reaction and a hydrolysis ratio above 2 , are most likely the cause for large particle formation and deposition within the microscale structures. Besides the inhomogeneous reactant concentrations subsequently to the first mixer, the apparent $\mathrm{pH}$ (as denoted in Fig. 5b) serves as a measure to estimate stabilization of $\mathrm{TiO}_{2}$ particles by $\mathrm{pH}$, as described by Su et al. [63]. As stated in the Introduction of the present paper, the $\mathrm{pH}$ measured in organic solvents cannot directly be related to $\mathrm{pH}$ measurements in water as a solvent. Additionally, it has to be noted that the modelled apparent $\mathrm{pH}$ values higher than seven are the result of dilution of the nitric acid/hydronium ions by the diffusion gradient. Furthermore, protolysis of the respective parent alcohol was neglected. However, an apparent $\mathrm{pH}$ above 3 still causes a lack of stabilization of $\mathrm{TiO}_{2}$ particles $<3 \mathrm{~nm}$ due to decrease in the particles zeta potential [41]. Unstabilized conditions are thus present within wide sections of the microfluidic mixing zone, as depicted in Fig. 5b. If the hydrolysis ratio has been increased due to hygroscopicity of the 2-propanol, this can additionally cause fouling. If water is present in the TTIP feed, the temperature increase in the heat exchanger directly before the LH2 slit plate mixer increases the reaction speed. This may cause additional particle precipitation and fouling in the micromixer prior to stabilization.

Known reaction kinetics for $\mathrm{TiO}_{2}$-particle induction times (Eqs. (1) and (2)) do not offer a distinctive correction for $\mathrm{pH}$ and are only valid at 


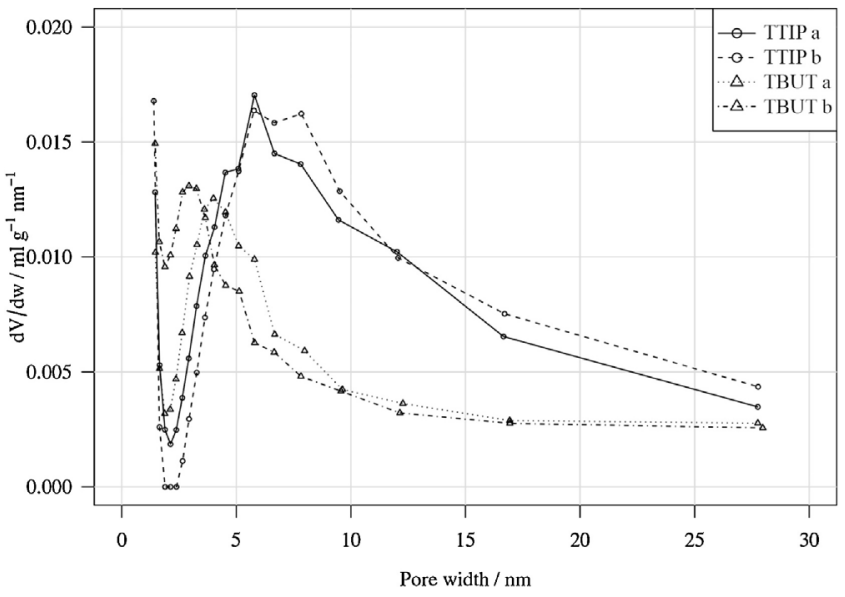

Fig. 6. The pore size distributions of the catalysts gained by evaluation of the nitrogen adsorption isotherm according to the BJH method for catalysts made from titanium(IV) isopropoxide (circles) and titanium(IV)butoxide (triangles). a and b indicate measurements for independent catalyst production processes.

a limited hydrolysis ratio range. Thus, kinetic modelling of the induction time of titanium dioxide particles from alkoxide precursors could not be applied to the mixing model. However, the published kinetics for TBUT indicate an induction time which is three to four orders of magnitude longer than that for TTIP. An estimation of induction time for the perfectly mixed reactants, under consideration of the Arrhenius equation based on the data obtained by Park et al. [64] (for further information please refer to SI, Eqs. (3)-(6), Table 1), but neglecting the $\mathrm{pH}$ influence, results in induction times of $33 \mathrm{~s}$ and $657 \mathrm{~s}$ for TTIP and TBUT as precursors respectively. This scenario assumes the complete mixing of both reactants before any reaction takes place. The diffusion simulation shows that such optimal conditions are not present. However, this estimation of the induction time allows the relation of mixingand reaction times to be approximated. The respective Damköhler numbers for mixing derived from these numbers are $3.5 \cdot 10^{-2}$ for TTIP and $2.6 \cdot 10^{-3}$ for TBUT respectively. This additionally underlines the influence of micromixing on the particle formation and fouling within the microstructures of the LH2 slit plate mixer for use of TTIP as precursor as well as the fouling remediation by use of TBUT, as a Damköhler number between $10^{2}$ and $10^{-2}$ indicates a competition of mixing and reaction [48-50]. Calculation of the Stokes and Péclet Numbers for particle sizes measured after the LH2 slit plate mixer does not provide further insight into the particle deposition mechanism, as the Péclet number is larger than $10^{6}$ and the stokes number is smaller than $5 \cdot 10^{-2}$ for all particles formed in the LH2 slit plate (Table 1). The respective values for nucleation time, mixing time, Damköhler, Stokes and Péclet number are summarized in Table 1.

\subsection{Physical properties of nanoparticles produced with TTIP and TBUT}

Despite the fouling problem of TTIP as a precursor, both processes yielded phosphate $\mathrm{TiO}_{2}$ particles of anatase modification (Raman spectra can be found in Fig. 2 of the SI). Nitrogen adsorption shows a higher adsorbed $\mathrm{N}_{2}$ volume for catalysts made from TTIP (as shown in Fig. 6). The respective nitrogen adsorption isotherms are depicted in Fig. 3 of the SI. The pore size distribution derived from nitrogen adsorption shows that the pore size of TTIP derived $\mathrm{P}_{-} \mathrm{TiO}_{2}$ is larger than that of catalyst produced with TBUT (as shown in Fig. 6).

However, the porosity of the TBUT catalyst is lower with $0.139 \mathrm{~mL} \mathrm{~g}^{-1}$ compared to $0.242 \mathrm{~mL} \mathrm{~g}^{-1}$ for the TTIP catalyst. This is in line with the published trends as the slower reaction/nucleation rate results in formation of more compact $\mathrm{TiO}_{2}$ particles when TBUT is used. Similar effects have been observed by Faleras et al. [65]. The difference in porosity is depicted in the scanning electron microscope image in Fig. 7. While the catalyst produced with TTIP consists of a fine network (Fig. 7B), the one produced from TBUT features an agglomeration of small compact spheres (Fig. 7A) (Table 2).

The primary particle size distributions at the end of the microreactor with a mean particle size of $2.4 \pm 0.1 \mathrm{~nm}$ (TBUT) and $2.2 \pm 0.1 \mathrm{~nm}$ (TTIP) do not show significant differences between experiments (see Table 2 and Fig. 4 in the SI). As mentioned earlier, homogenization effects of the valve mixer in the third reactions step are a plausible explanation for the decrease of TTIP particle size and increased uniformity of the particles at the outlet compared to measurements after the first mixer.

\subsection{Conversion of glucose to 5-HMF}

$\mathrm{P}^{-\mathrm{TiO}_{2}}$ catalyst particles derived from TBUT and TTIP were exemplarily used for 5-HMF synthesis and yielded ca. $40 \%$ of 5-HMF from glucose while conversion was over $90 \%$ for all catalyst samples. While the original works of Atanda et al. report 5-HMF yields of up to $90 \%$, those high yields were achieved under a defined pressure of $20 \mathrm{bar}$ [44]. The utilization of a microwave reactor with rapid heating/cooling and lack of pressure control within the microwave reactor at least partially explains the lower yields compared to literature data, as a higher degree of polymerization of the produced 5-HMF is expected to cause the low yield compared to the works of Atanda et al. The partition of the catalytically more active anatase modification of the $\mathrm{P}_{-} \mathrm{TiO}_{2}$ in relation to the rutile and brookite modified partitions was not evaluated during our study. Quantification of the different crystal modification partition was able to provide further insights and allow optimization of the catalyst.

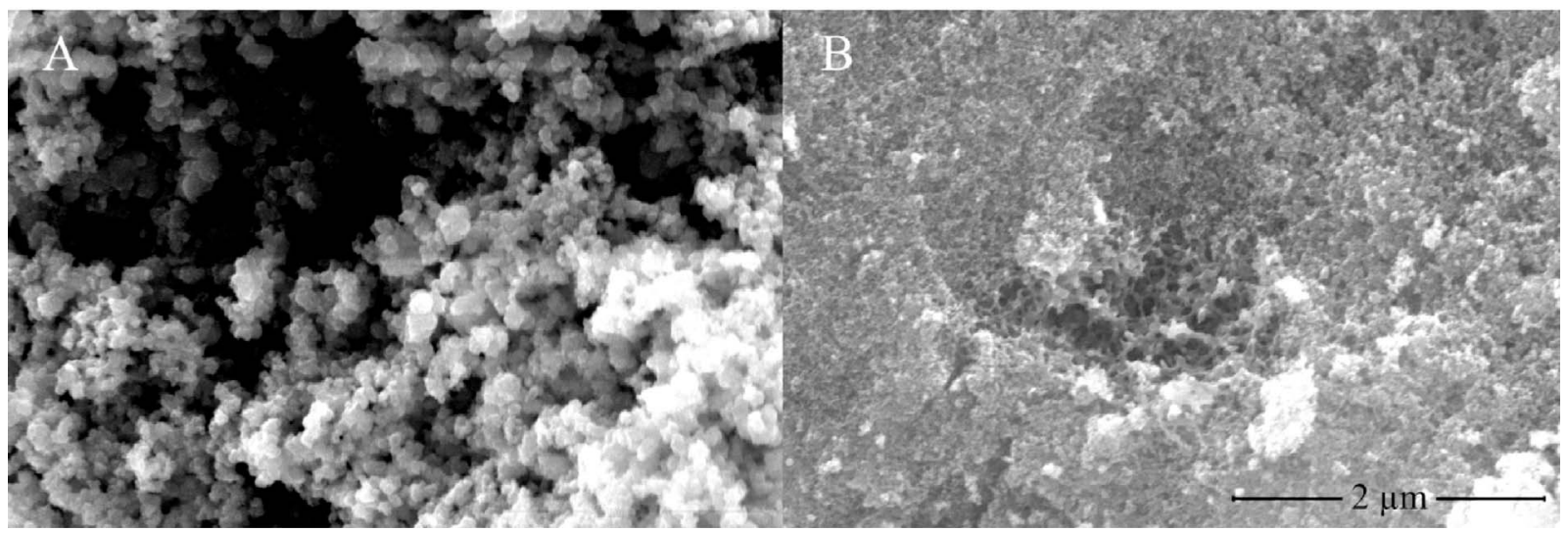

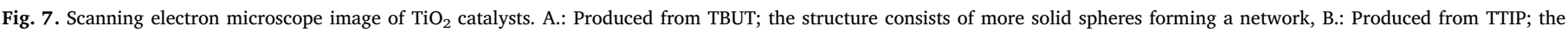
structure is a fine more homogenic network. 
Table 2

Summary of $\mathrm{P}-\mathrm{TiO}_{2}$ catalyst particle properties.

\begin{tabular}{|c|c|c|c|c|c|c|}
\hline Substrate & Mean primary particle size $(\mathrm{nm})$ & Porosity $\left[\mathrm{mL} \mathrm{g}^{-1}\right]$ & Specific surface $\left[\mathrm{m}^{2} \mathrm{~g}^{-1}\right]$ & Modification & 5-HMF yield [\%] & Glucose conversion [\%] \\
\hline \multirow[t]{2}{*}{ Titanium(IV) isopropoxide } & 2.3 & 0.232 & 90 & Anatase & 46.5 & 90.7 \\
\hline & 2.5 & 0.252 & 85 & Anatase & 43.1 & 96.9 \\
\hline \multirow[t]{2}{*}{ Titanium(IV) butoxide } & 2.1 & 0.141 & 66 & Anatase & 44.2 & 100 \\
\hline & 2.3 & 0.136 & 76 & Anatase & 40.6 & 91.6 \\
\hline
\end{tabular}

\section{Conclusion}

This work clearly elucidates the importance of controlling particle formation for intensified processes applying microreactor technology and involving solids. It is demonstrated that fouling, as one of the main obstacles for industrial scale microreactor synthesis of nanoparticles, can be remediated. The data presented demonstrates that tuning of reaction and mixing times becomes invaluable for remediation of fouling during the synthesis of phosphate modified $\mathrm{TiO}_{2}$ particles in microstructured devices. The first of the three consecutive reaction steps was identified as the crucial operation in terms of fouling remediation. The change of the alkoxide precursor from TTIP to TBUT was used to remediate fouling and the rapid nucleation/precipitation of TTIP was identified as the cause of increasing backpressure. DLS measurement of particle size distribution after the critical reaction step was employed, and particles sizes larger than $5 \mathrm{~nm}$ were found only when TTIP was used as precursor. The underlying concentration gradients during the critical timeframe within the micromixing structures were investigated by diffusion simulation. The hydrolysis ratio of the reaction, as well as the apparent $\mathrm{pH} / \mathrm{H}_{3} \mathrm{O}^{+}$within the Ehrfeld LH2 slit plate mixer, showed large gradients of reaction conditions within the microfluidic structures within the Ehrfeld LH2 slit plate micromixer. The Damköhler numbers were calculated based on estimated mixing and reaction/nucleation times. These numbers indicated a competition of mixing and reaction as the underlying cause for particulate fouling within the LH2 slit plate mixer for use of TTIP as a precursor, and thus provide a plausible explanation for fouling remediation when using TBUT. The resulting catalysts were characterized thoroughly, and exemplarily used for 5-HMF synthesis with a yield of 40\% 5-HMF. Catalytic results were comparable for both substrates, despite differences in porosity and surface area. Optimization of the catalyst by tuning substrate concentrations and reaction parameters can be used to increase 5-HMF yield. Additionally, fine tuning of the 5-HMF synthesis in the microwave reactor is a promising approach to exploit the full potential of the produced phosphate modified titania catalysts.

\section{Acknowledgments}

The authors wish to thank the European Commission for supporting this work as part of the research project "Intensified by Design platform for the intensification of processes involving solids handling", IbD", under the H2020 SPIRE programme (SPIRE-08-2015-680565). This work was supported by the Swiss State Secretariat for Education, Research and Innovation (SERI) under contact number 15.0246. The opinions expressed and arguments employed herein do not necessarily reflect the official views of the supporting organizations. We furthermore thank our colleagues Brenno Zucchetti, Oliver Martin, Elias August and Nicole Bolzli for many fruitful scientific discussions and input on the project.

\section{Appendix A. Supplementary data}

Supplementary data associated with this article can be found, in the online version, at http://dx.doi.org/10.1016/j.cep.2017.07.024.

\section{References}

[1] A.I. Stankiewicz, J.A. Moulijn, Process intensification, Ind. Eng. Chem. 41 (2002) 1920-1924, http://dx.doi.org/10.1021/ie011025p.

[2] B. Gutmann, D. Cantillo, C.O. Kappe, Continuous-Flow technology - a tool for the safe manufacturing of active pharmaceutical ingredients, Angew. Chemie - Int. Ed. 54 (2015) 6688-6728, http://dx.doi.org/10.1002/anie.201409318.

[3] D.M. Roberge, M. Gottsponer, M. Eyholzer, N. Kockmann, Industrial design scaleup, and use of microreactors, Chim. Oggi. 27 (2009) 8-11.

[4] N. Kockmann, M. Gottsponer, B. Zimmermann, D.M. Roberge, Enabling continuousFlow chemistry in microstructured devices for pharmaceutical and fine-chemical production, Chem. - Eur. J. 14 (2008) 7470-7477, http://dx.doi.org/10.1002/ chem. 200800707.

[5] W. Ehrfeld, Design guidelines and manufacturing methods for microreaction devices, Chimia (Aarau) 56 (2002) 598-604, http://dx.doi.org/10.2533/ 000942902777680045.

[6] R. Wohlgemuth, I. Plazl, P. Žnidaršič-Plazl, K.V. Gernaey, J.M. Woodley, Microscale technology and biocatalytic processes: opportunities and challenges for synthesis, Trends Biotechnol. 33 (2015) 1-13, http://dx.doi.org/10.1016/j.tibtech.2015.02. 010.

[7] V. Kumar, K.D.P. Nigam, Process intensification in green synthesis, Green Process Synth. 1 (2012) 79-107, http://dx.doi.org/10.1515/greenps-2011-0003.

[8] D.T. McQuade, P.H. Seeberger, Applying flow chemistry: methods, materials, and multistep synthesis, J. Org. Chem. 78 (2013) 6384-6389, http://dx.doi.org/10. 1021/jo400583m.

[9] C.A. Serra, D. Parida, F. Bally, D.K. Garg, Y. Hoarau, V. Hessel, Micro-chemical plants, The Encyclopedia of Polymer Science and Technology, John Wiley \& Sons, Inc., Hoboken, NJ, USA, 2013, http://dx.doi.org/10.1002/0471440264.pst612.

[10] V. Hessel, S. Hardt, H. Löwe, Chemical Micro Process Engineering Fundamentals, Modelling and Reactions, 1st ed., Wiley-VCH Verlag GmbH \& Co KGaA, Grünstadt, 2004.

[11] M. Poux, P. Cognet, C. Goudon, Green Process Engineering From Concepts to Industrial Application, 1st ed., CRC Press Taylor \& Francis Group, Paris, 2015

[12] A. Pohar, I. Plazl, Process intensification through microreactor application, Chem. Biochem. Eng. Q. 23 (2009) 537-544.

[13] K.S. Elvira, R.C.R. Casadevall i Solvas, A.J. de Mello, The past, present and potential for microfluidic reactor technology in chemical synthesis, Nat. Chem. 5 (2013) 905-915, http://dx.doi.org/10.1038/nchem.1753.

[14] P. Riedlberger, D. Weuster-Botz, New miniature stirred-tank bioreactors for parallel study of enzymatic biomass hydrolysis, Bioresour. Technol. 106 (2012) 138-146, http://dx.doi.org/10.1016/j.biortech.2011.12.019.

[15] D. Jussen, H. Soltner, B. Stute, W. Wiechert, E. von Lieres, M. Pohl, $\mu$ MORE: a microfluidic magnetic oscillation REactor for accelerated parameter optimization in biocatalysis, J. Biotechnol. 231 (2016) 174-182, http://dx.doi.org/10.1016/j. jbiotec.2016.06.006.

[16] J. Bolivar, J. Wiesbauer, B. Nidetzky, Biotransformations in microstructured reactors: more than flowing with the stream? Trends Biotechnol. 29 (2011) 333-342, http://dx.doi.org/10.1016/j.tibtech.2011.03.005.

[17] J.M. Köhler, B.P. Cahill, Micro-Segmented Flow Applications in Chemistry and Biology, 1st ed., Springer-Verlag, Berlin Heidelberg, 2014, http://dx.doi.org/10. 1007/978-3-642-38780-7.

[18] S.T. Poschenrieder, S.G. Wagner, K. Castiglione, Efficient production of uniform nanometer-sized polymer vesicles in stirred-tank reactors, J. Appl. Polym. Sci. 133 (2016) 1-10, http://dx.doi.org/10.1002/app.43274.

[19] N. Kockmann, M. Engler, P. Woias, Particulate fouling in micro-structured devices, Proc. 6th Int. Conf. Heat Exch. Fouling Clean. (2005) 191-196.

[20] M. Schoenitz, L. Grundemann, W. Augustin, S. Scholl, Fouling in microstructured devices: a review, Chem. Commun. 51 (2015) 8213-8228, http://dx.doi.org/10. 1039/C4CC07849G.

[21] M. Mayer, J. Bucko, W. Benzinger, R. Dittmeyer, W. Augustin, S. Scholl, Modeling fouling factors for microscale heat exchangers, Exp. Heat Transf. 28 (2014) 222-243, http://dx.doi.org/10.1080/08916152.2013.854284.

[22] K. Wu, S. Kuhn, Strategies for solids handling in microreactors, Chim. Oggi/Chem. Today 32 (2014) 62-66.

[23] R.L. Hartman, Managing solids in microreactors for the upstream continuous processing of fine chemicals, Org. Process Res. Dev. 16 (2012) 870-887, http://dx.doi. org/10.1021/op200348t.

[24] H. Wang, A. Mustaffar, A.N. Phan, V. Zivkovic, D. Reay, R. Law, K. Boodhoo, A review of process intensification applied to solids handling, Chem. Eng. Process. Process Intensif. 118 (2017) 78-107, http://dx.doi.org/10.1016/j.cep.2017.04. 007.

[25] T.W. Phillips, I.G. Lignos, R.M. Maceiczyk, A.J. deMello, J.C. deMello, Nanocrystal synthesis in microfluidic reactors: where next? Lab Chip. 14 (2014) 3172-3180, 
http://dx.doi.org/10.1039/c4lc00429a.

[26] S.E. Skrabalak, R.L. Brutchey, Going with the flow: continuous flow routes to colloidal nanoparticles, Chem. Mater. 28 (2016) 1003-1005, http://dx.doi.org/10. 1021/acs.chemmater.6b00472.

[27] D.P. MacWan, P.N. Dave, S. Chaturvedi, A review on nano-TiO2 sol-gel type syntheses and its applications, J. Mater. Sci. 46 (2011) 3669-3686, http://dx.doi. org /10.1007/s10853-011-5378-y.

[28] G. Meacock, K.D.A. Taylor, M.J. Knowles, A. Himonides, The improved whitening of minced cod flesh using dispersed titanium dioxide, J. Sci. Food Agric. 73 (1997) 221-225, http://dx.doi.org/10.1002/(SICI)1097-0010(199702)73:2<221:AIDJSFA708 > 3.0.CO;2-U.

[29] C.O. Hendren, X. Mesnard, J. Dröge, M.R. Wiesner, Estimating production data for five engineered nanomaterials as a basis for exposure assessment, Environ. Sci. Technol. 45 (2011) 2562-2569, http://dx.doi.org/10.1021/es103300g.

[30] F. Dutschke, J. Irrgeher, D. Pröfrock, Optimisation of an extraction/leaching procedure for the characterisation and quantification of titanium dioxide (TiO 2) nanoparticles in aquatic environments using SdFFF-ICP-MS and SEM-EDX analyses, Anal. Methods 9 (2017) 3626-3635, http://dx.doi.org/10.1039/C7AY00635G.

[31] M. Murali, P. Athif, S. HE, H. Basu, Synthesis and characterization of TiO2 nanoparticle and study of its impact on aquatic organism, JOAASR 1 (2016) 10-23 http://joaasr.com/index.php/joaasr/article/view/30.

[32] S.M. Gupta, M. Tripathi, A review on the synthesis of TiO2 nanoparticles by solution route, Cent. Eur. J. Chem. 10 (2012) 279-294, http://dx.doi.org/10.2478/ s11532-011-0155-y.

[33] K.S. Yoo, Synthesis of TiO2 materials using ionic liquids and its applications for sustainable energy and environment, J. Nanosci. Nanotechnol. 16 (2016) 4302-4309, http://dx.doi.org/10.1166/jnn.2016.10969.

[34] L. Atanda, S. Mukundan, A. Shrotri, Q. Ma, J. Beltramini, Catalytic conversion of glucose to 5-Hydroxymethyl-furfural with a phosphated TiO 2 catalyst, ChemCatChem 7 (2015) 781-790, http://dx.doi.org/10.1002/cctc.201402794.

[35] Z.R. Ismagilov, L.T. Tsikoza, N.V. Shikina, V.F. Zarytova, V.V. Zinoviev, S.N. Zagrebelnyi, Synthesis and stabilization of nano-sized titanium dioxide, Russ. Chem. Rev. 78 (2009) 873-885, http://dx.doi.org/10.1070/ RC2009v078n09ABEH004082.

[36] R. Azouani, A. Soloviev, M. Benmami, K. Chhor, J.-F. Bocquet, A. Kanaev, Stability and growth of titanium-oxo-alkoxy TixOy(OiPr)z clusters, J. Phys. Chem. C. 111 (2007) 16243-16248, http://dx.doi.org/10.1021/jp073949h.

[37] A. Soloviev, R. Tufeu, C. Sanchez, A.V. Kanaev, Nucleation stage in the Ti(OPri)4 sol-gel process, J. Phys. Chem. B. 105 (2001) 4175-4180, http://dx.doi.org/10. 1021/jp0040190.

[38] A. Soloviev, H. Jensen, E.G. Søgaard, A.V. Kanaev, Aggregation kinetics of sol-gel process based on titanium tetraisopropoxide, J. Mater. Sci. 38 (2003) 3315-3318, http://dx.doi.org/10.1023/A:1025198323886.

[39] N.V. Golubko, M.I. Yanovskaya, I.P. Romm, A.N. Ozerin, Hydrolysis of titanium alkoxides: thermochemical, electron microscopy, saxs studies, J. Sol-Gel Sci. Technol. 20 (2001) 245-262, http://dx.doi.org/10.1023/A:1008769918083.

[40] S. Mohammadi, A. Harvey, K.V.K. Boodhoo, Synthesis of TiO2 nanoparticles in a spinning disc reactor, Chem. Eng. J. 258 (2014) 171-184, http://dx.doi.org/10. 1016/j.cej.2014.07.042.

[41] M.E. Simonsen, E.G. Søgaard, Sol-gel reactions of titanium alkoxides and water: influence of $\mathrm{pH}$ and alkoxy group on cluster formation and properties of the resulting products, J. Sol-Gel Sci. Technol. 53 (2010) 485-497, http://dx.doi.org/10. 1007/s10971-009-2121-0.

[42] S. Rondinini, $\mathrm{pH}$ measurements in non-aqueous and aqueous-organic solvents definition of standard procedures, Anal. Bioanal. Chem. 374 (2002) 813-816, http://dx.doi.org/10.1007/s00216-002-1455-z.

[43] D. Himmel, S.K. Goll, I. Leito, I. Krossing, Anchor points for the unified Brönsted acidity scale: the rCCC model for the calculation of standard Gibbs energies of proton solvation in eleven representative liquid media, Chem. - Eur. J. 17 (2011) 5808-5826, http://dx.doi.org/10.1002/chem.201003164.
[44] L. Atanda, A. Shrotri, S. Mukundan, Q. Ma, M. Konarova, J. Beltramini, Direct production of 5-hydroxymethylfurfural via catalytic conversion of simple and complex sugars over phosphated TiO2, ChemSusChem 8 (2015) 2907-2916, http:// dx.doi.org/10.1002/cssc.201500395.

[45] K. Nakajima, R. Noma, M. Kitano, M. Hara, Titania as an early transition metal oxide with a high density of lewis acid sites workable in water, J. Phys. Chem. C. 117 (2013) 16028-16033, http://dx.doi.org/10.1021/jp404523r.

[46] K. Nakajima, R. Noma, M. Kitano, M. Hara, Selective glucose transformation by titania as a heterogeneous Lewis acid catalyst, J. Mol. Catal. A Chem. 388-389 (2014) 100-105, http://dx.doi.org/10.1016/j.molcata.2013.09.012.

[47] M.N. Kashid, A. Renken, L. Kiwi-Minsker, Microstructured Devices for Chemical Processing, 1st ed., Wiley-VCH Verlag GmbH \& Co., Weinheim, Germany, 2015.

[48] S.I.A. Shah, L.W. Kostiuk, S.M. Kresta, The effects of mixing, reaction rates, and stoichiometry on yield for mixing sensitive reactions - part I: model development, Int. J. Chem. Eng. (2012), http://dx.doi.org/10.1155/2012/750162.

[49] S.I.A. Shah, L.W. Kostiuk, S.M. Kresta, The effects of mixing, reaction rates, and stoichiometry on yield for mixing sensitive reactions - part II: design protocols, Int. J. Chem. Eng. (2012) 2012, http://dx.doi.org/10.1155/2012/654321.

[50] E.L. Paul, V. a Atiemo-Obeng, S.M. Kresta, Handbook of Industrial Mixing Science and Practice, 1st ed., John Wiley \& Sons, Inc., Hoboken, New Jersey, 2004, http:// dx.doi.org/10.1002/0471451452.

[51] R. Azouani, A. Michau, K. Hassouni, K. Chhor, J.-F. Bocquet, J.-L. Vignes, A. Kanaev, Elaboration of pure and doped TiO2 nanoparticles in sol-gel reactor with turbulent micromixing: application to nanocoatings and photocatalysis, Chem. Eng. Res. Des. 88 (2010) 1123-1130, http://dx.doi.org/10.1016/j.cherd.2009.10. 001.

[52] M. Bednarzik, C. Waberski, I. Rudolph, B. Löchel, F. Herbstritt, G. Ahrens, Mixer slit plates fabricated by direct-LIGA, Microsys Technol. 14 (2008) 1765-1770, http:// dx.doi.org/10.1007/s00542-008-0569-4.

[53] K. Rodermund, F. Schael, F. Herbstritt, J. Heck, M. Grünewald, Mikrostrukturierte Mischer und Hydrozyklone zur Mehrphasenkontaktierung und - trennung, Chemie Ing. Tech. 83 (2011) 1036-1043, http://dx.doi.org/10.1002/cite.201100020.

[54] Ehrfeld Mikrotechnik AG, Kammförmiger Mikrovermischer, DE 20209009 U 1, 2002.

[55] F. Ehrfeld, T. Herbstritt, Micromixer 12 (2011) (US007934865B2).

[56] A. Wolf, V. Michele, O.F.-K. Schlüter, F. Herbstritt, J. Heck, L. Mleczko, Precipitation in a micromixer - from laboratory to industrial scale, Chem. Eng. Technol. 38 (2015) 2017-2024, http://dx.doi.org/10.1002/ceat.201500040.

[57] D. Xie, J. Zhou, S. Tian, L. Mleczko, X. Zhou, A comparative study of clogging in valve and cascade mixers, Chem. Eng. Technol. (2016) 1-11, http://dx.doi.org/10. 1002/ceat.201500756.

[58] E.P. Barrett, L.G. Joyner, P.P. Halenda, The determination of pore volume and area distributions in porous substances. I. computations from nitrogen isotherms, J. Am. Chem. Soc. 73 (1951) 373-380, http://dx.doi.org/10.1021/ja01145a126.

[59] S. Brunauer, P.H. Emmett, E. Teller, Adsorption of gases in multimolecular layer, J. Am. Chem. Soc. 60 (1938) 309-319 (citeulike-article-id:4074706).

[60] G.G. Hawley, R.J. Lewis, Hawley's Condensed Chemical Dictionary, 13th ed., International Thomson Publishing Services, New York, NY, 1997.

[61] J. Getze, Mikroreaktionstechnik als Syntheseverfahren zur Darstellung von innovativen Materialien, Philipps-Universität Marburg, 2008.

[62] A.G. Ehrfeld Mikrotechnik, Design and Function of the LH2 Micromixer, (2016).

[63] C. Su, B.-Y. Hong, C.-M. Tseng, Sol-gel preparation and photocatalysis of titanium dioxide, Catal. Today 96 (2004) 119-126, http://dx.doi.org/10.1016/j.cattod. 2004.06.132.

[64] J.K. Park, J.J. Myoung, J.B. Kyong, H.K. Kim, Reaction mechanism for the hydrolysis of titanium alkoxides, Bull. Korean Chem. Soc. 24 (2003) 671-673, http://dx doi.org/10.5012/bkcs.2003.24.5.671.

[65] P. Falaras, A.P. Xagas, Roughness and fractality of nanostructured TiO 2 films prepared via sol-gel technique, J. Mater. Sci. 37 (2002) 3855-3860. 